\title{
EFEITOS DA SUPLEMENTAÇÃO ENZIMÁTICA E DA FORMA FÍSICA DA RAÇÃO SOBRE O DESEMPENHO E AS CARACTERÍSTICAS DE CARCAÇA DE FRANGOS DE CORTE ${ }^{1}$
}

\author{
Effects of enzyme supplementation and different phisical forms of diets \\ on performance and carcass characteristics of broilers chicken
}

\author{
Renata Mara de Souza ${ }^{2}$, Antônio Gilberto Bertechini ${ }^{3}$, Raimundo Vicente de Sousa ${ }^{4}$, \\ Paulo Borges Rodrigues ${ }^{3}$, Júlio César Carrera de Carvalho ${ }^{5}$, Jerônimo Ávito Gonçalves de Brito ${ }^{5}$
}

\begin{abstract}
RESUMO
Um experimento foi conduzido para avaliar o efeito da suplementação do complexo enzimático Endopower $\beta^{\circledR}$, composto de $\alpha$-galactosidase, galactomanase, xilanase e $\beta$-glucanase e da forma física da ração sobre o desempenho e as características de carcaça de frangos de corte. Foram utilizados 1488 frangos de corte machos, distribuídos num delineamento inteiramente casualizado, oito tratamentos e seis repetições. Os tratamentos constituíram-se de rações à base de milho e de farelo de soja, sem adição de enzimas ou com 200 ou 400 g de enzimas por tonelada de ração e duas formas físicas (farelada e peletizada). Dois tratamentos adicionais continham dieta basal farelada com energias do milho e farelo de soja valorados em 2 e $9 \%$, respectivamente e digestibilidade de aminoácidos valorados em 4\% para ambos ingredientes, sendo um tratamento sem adição de enzimas e outro com a adição de $200 \mathrm{~g}$ por tonelada de ração. O desempenho foi avaliado de 1 a 21 dias e 1 a 42 dias de idade das aves. Houve efeito da suplementação enzimática no consumo de ração, nos dois períodos avaliados $(\mathrm{P}<0,05)$, o qual reduziu linearmente. A conversão alimentar melhorou $(\mathrm{P}<0,05)$ no período de 1-21 dias. O teor de gordura abdominal aumentou linearmente $(\mathrm{P}<0,05)$. Houve interação entre suplementação enzimática e forma física da ração na conversão alimentar $(\mathrm{P}<0,01)$ e ganho de peso $(\mathrm{P}<0,05)$ no período de 1-42 dias, sendo a forma peletizada sem enzimas a que proporcionou melhor desempenho $(\mathrm{P}<0,05)$. $\mathrm{O}$ ganho de peso de 1-21 dias e o rendimento de carcaça foram superiores nas aves recebendo ração peletizada $(\mathrm{P}<0,05)$. A valoração do milho e do farelo de soja não afetou o desempenho $(\mathrm{P}>0,05)$ dos frangos de corte 1-21 dias de idade.
\end{abstract}

Termos para indexação: Enzimas exógenas, carboidrases, peletização, polissacarídeos não amiláceos.

\begin{abstract}
A study was conducted in order to verify the effect of enzyme supplementation (Endopower $\beta^{\circledR}$, based on de $\alpha$-galactosidase, galactomanase, xilanase e $\beta$-glucanase) and feeding different physical forms of diets on performance and carcass yield of broilers from 1 to 42 dais old. A total of 1488 broilers chickens, 8 treatments, 6 replicates and 31 broilers per experimental unit plot were fed with diets based on corn and soybean, with enzyme supplementation 200 or $400 \mathrm{~g}$ for ton. and without enzymes supplementation and two physical forms (meal and pelleted ). Two additional basal diets with the energetic values of corn and soybean meal valued in 2 and $9 \%$ respectively and digestibilidade of amino acids digestibility valued in $4 \%$ by using one treatment with no enzyme supplementation and another one with enzyme supplementation of $200 \mathrm{~g} / \mathrm{ton}$. Two periods $1-21$ and $22-42$ days old were evaluated. Reduced feed intake were observed in linear way $(\mathrm{P}<0.05)$ by the enzyme supplementation $(\mathrm{P}<0.05)$ in two periods. Broilers fed diets supplemented showed better feed conversion in the period of $1-21$ days $(\mathrm{P}<0.05)$. Percentage of abdominal fat increased linearly with the increase of the supplementation level of enzyme $(\mathrm{P}<0.05)$. The interaction between enzyme supplementation and physical form was significant $(\mathrm{P}<0.05)$ for weight gain $(\mathrm{P}<0.05)$ and feed conversion $(\mathrm{P}<0.01)$ in the period of 1-42 days old . Pelleted diets showed better weight gain in the 1- 21 days $(\mathrm{P}<0.05)$. The pelleted diet improved performance to the broilers fed diets without enzyme supplementation $(\mathrm{P}<0.05)$. The carcass yield and weight gain in the period of 1-21 days were better in broilers fed pelleted diets $(\mathrm{P}<0.05)$. $)$. The valued energetic data of corn and soybean meal shown any difference $(\mathrm{P}>0.05)$ on the broiler performance from 1 to 21 days old.
\end{abstract}

Index terms: Exougenous enzymes, carbohydrases, pelleting, non starch polysaccharides.

(Recebido em 4 de outubro de 2005 e aprovado em 5 de dezembro de 2006)

\footnotetext{
${ }^{1}$ Parte da Dissertação apresentada pela primeira autora à Universidade Federal de Lavras/UFLA como parte das exigências do curso de Mestrado em Nutrição de Monogástricos.

2Doutoranda no Departamento de Zootecnia da Universidade Federal de Viçosa/UFV - 36570-000 - Viçosa, MG - renatazoo@ig.com.br

${ }^{3} \mathrm{Dr}$. em Nutrição de Monogástricos, Professores do Departamento de Zootecnia da Universidade Federal de Lavras/UFLA - Cx. P. 3037 - $37200-000$ Lavras, MG - bertechini@ufla.br; pborges@ufla.br

${ }^{4} \mathrm{Dr}$. em Nutrição de Monogástricos, Professor do Departamento de Medicina Veterinária da Universidade Federal de Lavras/UFLA - Cx. P. 3037 37200-000 - Lavras, MG - rvsousa@ufla.br

${ }^{5}$ Doutorando no Departamento de Zootecnia da Universidade Federal de Lavras/UFLA - Cx. P. 3037 - 37200-000 - Lavras, MG - jucecacazoo@yahoo.com.br ; jejebrito@yahoo.com.br
} 


\section{INTRODUÇÃO}

Os efeitos benéficos de enzimas exógenas derivadas de microorganismos melhorando a digestibilidade dos nutrientes para aves são bem estabelecidos. Porém, as condições de processamento das rações como a peletização, podem afetar a termoestabilidade destes aditivos, prejudicando seu efeito esperado.

A maioria das pesquisas são feitas baseadas no uso de enzimas em dietas contendo nutrientes com altas quantidades de polissacarídeos não amiláceos (PNAs), carboidratos resistentes à hidrólise no trato digestório de animais monogástricos e que agem prejudicando a absorção de nutrientes. No entanto, pesquisas utilizando enzimas exógenas em dietas à base de milho e farelo de soja são direcionadas para um melhor aproveitamento dos nutrientes contidos nestes ingredientes, principais componentes das rações utilizadas no Brasil.

Desse modo, o presente trabalho foi conduzido para determinar o efeito do complexo enzimático Endopower $\beta^{\circledR}$, composto de $\alpha$-galactosidase, galactomanase, xilanase e $\beta$-glucanase sobre o desempenho e características de carcaça de frangos de corte alimentados com dietas à base de milho e de farelo de soja e duas formas físicas (peletizada e farelada).

\section{MATERIAL E MÉTODOS}

O experimento foi conduzido no período de novembro a dezembro de 2004 e avaliou o desempenho e as características de carcaça dos frangos de corte. Foram utilizados 1488 pintos de corte machos da linhagem Cobb 500, adquiridos com um dia de idade, distribuídos em oito tratamentos e seis repetições. As aves foram alojadas em galpão de alvenaria, contendo 48 unidades experimentais com 31 aves cada, dotadas de bebedouros, comedouros e lâmpadas para aquecimento, onde foram criados até os 42 dias de idade. Foram utilizadas dois tipos de ração basal experimental isonutrientes, formuladas na base de aminoácidos digestíveis para as fases de 1 a 21 e 22 a 42 dias de idade, de acordo com as recomendações nutricionais sugeridas por Rostagno et al. (2000). Foram utilizadas duas rações basais, uma ração basal normal (DBN) e outra valorada (DBV), na qual a energia metabolizável do milho e da soja foram superestimados em 2,0 e 9,0\%, respectivamente e a digestibilidade de aminoácidos superestimada em $4 \%$ para ambos os ingredientes,. A composição percentual das rações encontra-se na Tabela 1 .
A partir das rações basais, foram constituídos os tratamentos:

1 - DBN; farelada; sem enzima

2 - DBN; farelada; $200 \mathrm{~g}$ de enzima /ton de ração

3 - DBN; farelada; $400 \mathrm{~g}$ de enzima /ton de ração

4 - DBN; peletizada; sem enzima

5 - DBN; peletizada; $200 \mathrm{~g}$ de enzima /ton de ração

6 - DBN; peletizada; 400 g de enzima /ton de ração

7 - DBV; farelada; sem enzima

8 - DBV; farelada; 200 g de enzima /ton de ração

O desempenho foi avaliado através do consumo de ração, ganho de peso e conversão alimentar nos períodos de 1 a 21 e 1 a 42 dias de idade das aves. Aos 42 dias, foram selecionadas duas aves de cada unidade experimental, as quais foram abatidas após jejum de 6 horas para avaliação de carcaça .

O modelo estatístico dos experimentos para todas as características avaliadas foi o seguinte:

$$
\mathrm{Y}_{\mathrm{ijk}}=\mu+\mathrm{E}_{\mathrm{i}}+\mathrm{FF}_{\mathrm{j}}+\mathrm{EFF}_{(\mathrm{ij})}+\mathrm{e}_{\mathrm{ij}}
$$

em que:

$\mathrm{Y}_{\mathrm{ijk}}=$ observação referente à enzima i, submetida à forma física j, na repetição $\mathrm{k}$.

$\mu=$ média geral

$\mathrm{E}_{\mathrm{i}}=$ efeito da enzima $\mathrm{i}, \mathrm{com} \mathrm{i}=1,2$ e 3

$\mathrm{FF}_{\mathrm{j}}=$ efeito da forma física $\mathrm{j}, \mathrm{com} \mathrm{j}=1$ e 2 .

$\mathrm{EFF}_{(\mathrm{ij})}=$ efeito da interação entre nível de enzima e forma física da ração.

$\mathrm{e}_{\mathrm{ij}}=$ erro experimental associado aos valores observados $\left(\mathrm{Y}_{\mathrm{ijk}}\right)$, que por hipótese tem distribuição normal com média zero e variância $\sigma^{2}$.

Para comparação dos tratamentos 7 e 8 , a análise estatística seguiu o modelo:

$$
\mathrm{Y}_{\mathrm{ij}}=\mu+\mathrm{T}_{\mathrm{i}}+\mathrm{e}_{\mathrm{ij}}
$$

$\mathrm{Y}_{\mathrm{ijk}}=$ observação referente ao tratamento i, na repetição $\mathrm{k}$. $\mu=$ média geral

$\mathrm{T}_{\mathrm{i}}=$ efeito do tratamento $\mathrm{i}$, com $\mathrm{i}=1$ e 2 .

$\mathrm{e}_{\mathrm{ij}}=$ erro experimental associado aos valores observados $\left(\mathrm{Y}_{\mathrm{ijk}}\right)$, que por hipótese tem distribuição normal com média zero e variância $\sigma^{2}$.

As análises estatísticas foram realizadas utilizandose o pacote estatístico SISVAR, descrito por Ferreira (2000), testando-se os efeitos dos tratamentos por meio da análise de regressão. Os contrastes foram testados pelo teste de Scheffé, comparando-se os tratamentos adicionais com os demais tratamentos correspondentes no mesmo nível de enzima. 
Tabela 1 -Composição percentual das rações, basal normal (DBN) e basal valorada(DBV) nas fases de 1 a 21 e 22 a 42 dias.

\begin{tabular}{|c|c|c|c|c|}
\hline \multirow{3}{*}{ Ingredientes } & \multicolumn{4}{|c|}{ Fases } \\
\hline & \multicolumn{2}{|c|}{1 a 21 dias } & \multicolumn{2}{|c|}{22 a 42 dias } \\
\hline & $\mathrm{DBN}$ & DBV & $\mathrm{DBN}$ & DBV \\
\hline Milho & 58,161 & 60,951 & 63,07 & 69,945 \\
\hline Farelo de soja & 35,204 & 34,684 & 30,00 & 29,572 \\
\hline Óleo de soja & 2,734 & 0,532 & 3,308 & 1,860 \\
\hline Calcário calcítico & 0,795 & 0,804 & 0,877 & 0,882 \\
\hline Fosfato bicálcico & 1,837 & 1,829 & 1,599 & 1,593 \\
\hline L-Lisina $\mathrm{HCl}$ & 0,172 & 0,130 & 0,173 & 0,181 \\
\hline DL-Metionina & 0,228 & 0,201 & 0,184 & 0,173 \\
\hline Sal comum iodado & 0,503 & 0,503 & 0,380 & 0,379 \\
\hline Suplemento vitamínico ${ }^{1,2}$ & 0,100 & 0,100 & 0,150 & 0,150 \\
\hline Suplemento mineral $^{3}$ & 0,100 & 0,100 & 0,100 & 0,100 \\
\hline Bacitracina de zinco $10 \%$ & 0,025 & 0,025 & 0,025 & 0,025 \\
\hline Salinomicina sódica $15 \%$ & 0,050 & 0,050 & 0,050 & 0,050 \\
\hline Cloreto de colina $60 \%$ & 0,04 & 0,04 & 0,04 & 0,04 \\
\hline Inerte (caulim) & 0,05 & 0,05 & 0,05 & 0,05 \\
\hline Total $(\mathrm{Kg})$ & \multicolumn{2}{|c|}{100,000} & \multicolumn{2}{|c|}{100,000} \\
\hline \multicolumn{5}{|l|}{ Composição Calculada } \\
\hline Energia Met. (kcal/kg) & \multicolumn{2}{|c|}{3000} & \multicolumn{2}{|c|}{3114} \\
\hline Proteína Bruta $(\%)$ & \multicolumn{2}{|c|}{21,00} & \multicolumn{2}{|c|}{19,3} \\
\hline Cálcio $(\%)$ & \multicolumn{2}{|c|}{0,900} & \multicolumn{2}{|c|}{0,860} \\
\hline Fósforo disponível (\%) & \multicolumn{2}{|c|}{0,450} & \multicolumn{2}{|c|}{0,400} \\
\hline Sódio (\%) & \multicolumn{2}{|c|}{0,200} & \multicolumn{2}{|c|}{0,190} \\
\hline Lis. digestível (\%) & \multicolumn{2}{|c|}{1,143} & \multicolumn{2}{|c|}{1,021} \\
\hline Met + Cis digestível (\%) & \multicolumn{2}{|c|}{0,807} & \multicolumn{2}{|c|}{0,720} \\
\hline
\end{tabular}

${ }^{1}$ Composição por kg de ração (1-21 dias): vit. A, 12.000 UI; vit. D3, 2.200 UI; vit. E 30 UI; vit. B1, 2,2 mg; vit B2, 6 mg; vit. B6, $3,3 \mathrm{mg}$; ác. pantotênico, $13 \mathrm{mg}$; biotina, 0,11mg; vit. K3, 2,5 mg; ácido fólico, 1mg; ácido nicotínico $530 \mathrm{mg}$; niacina, $25 \mathrm{mg}$;vit. B12, $16 \mu \mathrm{g}$; selênio, $0,25 \mathrm{mg}$; antioxidante $120 \mathrm{mg}$; e veículo QSP., $1 \mathrm{~g}$.

${ }^{2}$ Composição por kg de ração (22 a 42 dias): vit. A, 18.000 UI; vit. D3, 3.300 UI; vit. E 45 UI; vit. B1, 3,3 mg; vit B2, 9 mg; vit. B6, 4,95 mg; ác. pantotênico, 19,5 mg; biotina, 0,17mg; vit. K3, 3,75 mg; ácido fólico, 1,5 mg; ácido nicotínico 795 mg; niacina, 37,5 mg;vit. B12, $24 \mu \mathrm{g}$; selênio, 0,38 mg; antioxidante $180 \mathrm{mg}$; e veículo QSP., 1,5g.

${ }^{3}$ Composição por kg de ração: manganês, $75 \mathrm{mg}$; ferro, $20 \mathrm{mg}$; zinco, $50 \mathrm{mg}$; cobre, 4 mg; cobalto, 0,2 mg; iodo 1,5 mg e veículo QSP, $1 \mathrm{~g}$.

\section{RESULTADOS E DISCUSSÃO}

Os dados de desempenho nos dois períodos avaliados podem ser observados na Tabela 2 .

O consumo de ração nos dois períodos avaliados reduziu linearmente $(\mathrm{P}<0,05)$ à medida que houve aumento dos níveis do complexo enzimático nas rações (Figuras 1 e 2).

Sabendo-se que o principal efeito da adição de enzimas às dietas à base de milho e farelo de soja é a melhoria da digestibilidade dos nutrientes, e que as aves regulam o seu consumo de alimento pela ingestão de energia, os resultados deste experimento indicam um possível aumento no valor energético das rações em razão da suplementação enzimática. Entretanto, analisando-se os dados de consumo de ração para o período de 1 a 42 dias, observa-se redução linear no consumo de ração mas com uma equação apresentando coeficiente de determinação baixo em relação à do período de 1 a 21 dias. Vários autores (CAMIRUAGA et al., 2001; CONTE et al., 2002; GARCIA et al., 2000), suplementando dietas à base de milho e farelo de soja com enzimas, não verificaram diferenças estatísticas no consumo de ração. 

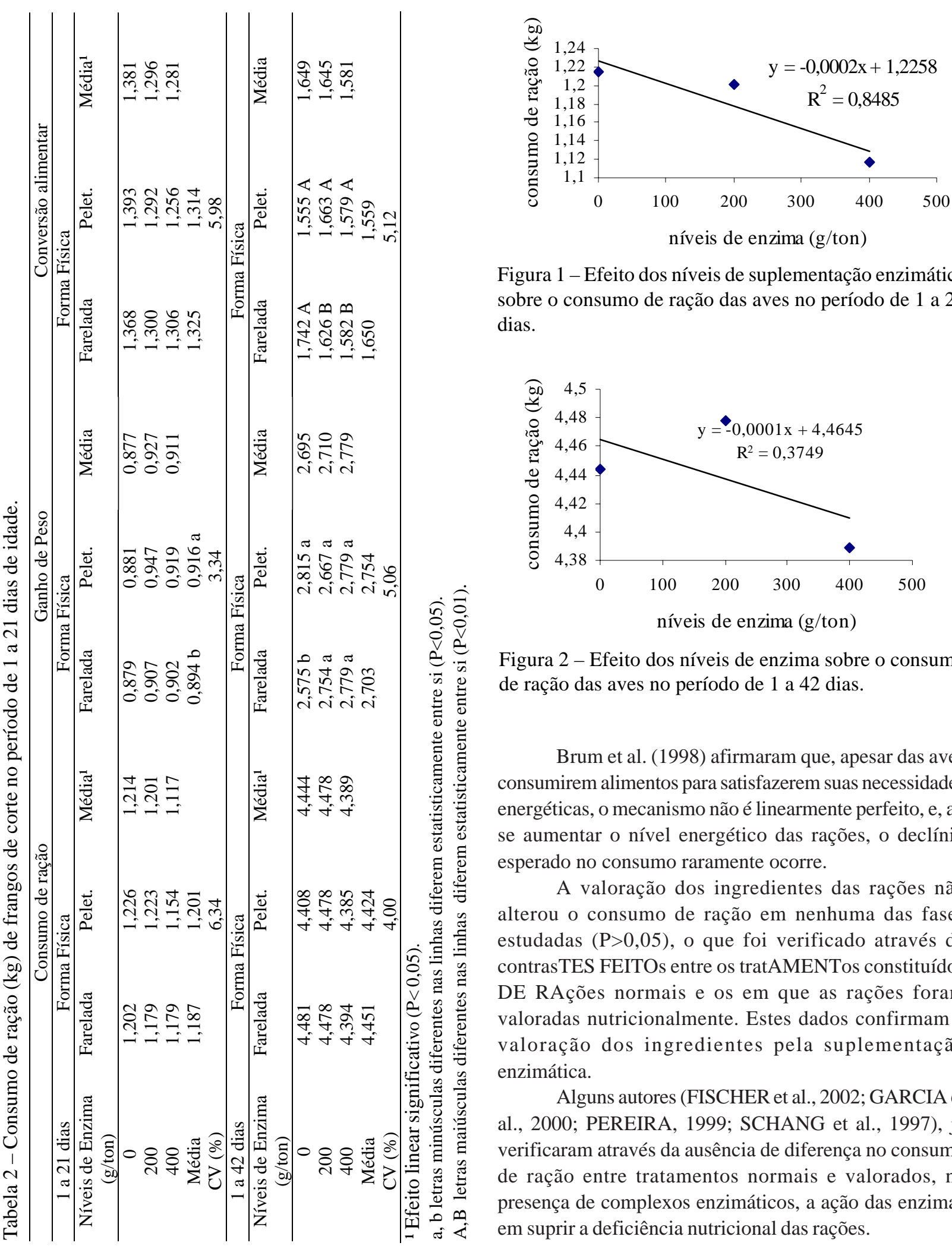

Figura 1 - Efeito dos níveis de suplementação enzimática sobre o consumo de ração das aves no período de 1 a 21 dias.

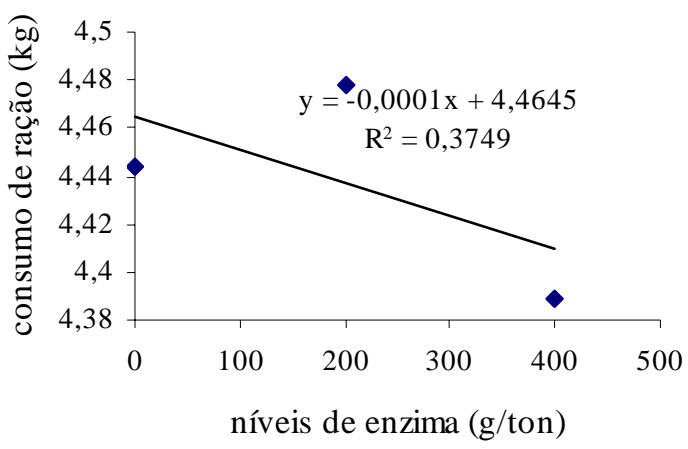

Figura 2 - Efeito dos níveis de enzima sobre o consumo de ração das aves no período de 1 a 42 dias.

Brum et al. (1998) afirmaram que, apesar das aves consumirem alimentos para satisfazerem suas necessidades energéticas, o mecanismo não é linearmente perfeito, e, ao se aumentar o nível energético das rações, o declínio esperado no consumo raramente ocorre.

A valoração dos ingredientes das rações não alterou o consumo de ração em nenhuma das fases estudadas $(\mathrm{P}>0,05)$, o que foi verificado através de contrasTES FEITOs entre os tratAMENTos constituídos DE RAções normais e os em que as rações foram valoradas nutricionalmente. Estes dados confirmam a valoração dos ingredientes pela suplementação enzimática.

Alguns autores (FISCHER et al., 2002; GARCIA et al., 2000; PEREIRA, 1999; SCHANG et al., 1997), já verificaram através da ausência de diferença no consumo de ração entre tratamentos normais e valorados, na presença de complexos enzimáticos, a ação das enzimas em suprir a deficiência nutricional das rações. 
No período de 1 a 21 dias, as aves que receberam ração peletizada apresentaram melhor ganho de peso em relação àquelas que receberam ração farelada $(\mathrm{P}<0,05)$. Estes resultados são semelhantes aos encontrados por (BRUM et al., 1998; ROLL, 1998; VARGAS et al., 2001). Esta diferença pode ser resultado do aumento da densidade de nutrientes proporcionada pelo processo de peletização e conseqüente redução do gasto energético com consumo de ração pelas aves.

Houve interação significativa $(\mathrm{P}<0,05)$ entre a forma física da ração e os níveis de suplementação do complexo enzimático no ganho de peso no período de 1 a 42 dias de idade das aves. $\mathrm{O}$ ganho de peso foi superior para a ração peletizada sem a suplementação do complexo enzimático. Este fato sugere uma influência, exercida pelo processo de peletização, na estabilidade enzimática.

O ganho de peso não foi alterado $(\mathrm{P}>0,05)$, nas duas fases analisadas, em virtude da valoração dos ingredientes que constituíram as rações experimentais, o que confirma a hipótese da valoração dos ingredientes pela suplementação enzimática.

Resultados semelhantes foram encontrados por Fisher et al. (2002), Garcia et al. (2000) e Pereira (1999).

Houve melhoria linear $(\mathrm{P}<0,05)$ na conversão alimentar no período de 1 a 21 dias de idade dos frangos de corte, atribuída à redução do consumo de ração sem afetar o ganho de peso das aves à medida que se elevaram os níveis de suplementação do complexo enzimático (Figura 3).

Estes dados estão de acordo com Fischer et al. (2002) e Torres et al. (2001), os quais verificaram melhoria na conversão alimentar neste período em frangos de corte

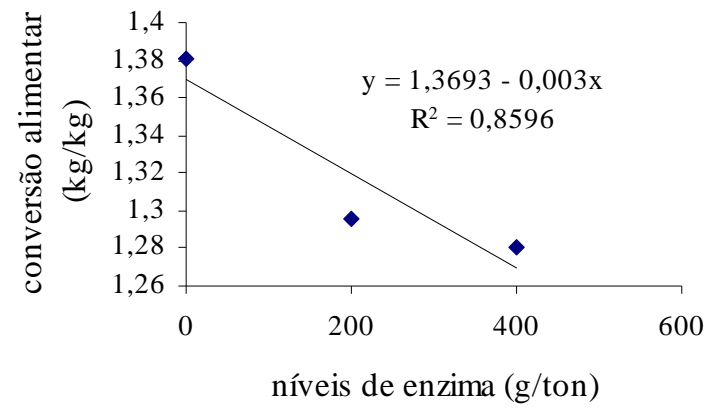

Figura 3 - Efeito dos níveis de enzima sobre a conversão alimentar das aves no período de 1 a 21 dias. suplementados com enzimas em dietas à base de milho e farelo de soja.

No período de 1 a 42 dias de idade das aves, houve interação significativa $(\mathrm{P}<0,01)$ entre nível de enzima e forma física da ração. A forma física peletizada sem adição do complexo enzimático foi a que apresentou melhor conversão alimentar $(\mathrm{P}<0,05)$, o que pode ser resultado de uma desestabilização enzimática provocada pelo processo de peletização.

A valoração dos ingredientes das rações não alterou a conversão alimentar das aves nos dois períodos avaliados $(\mathrm{P}>0,05)$. Possivelmente pela capacidade da suplementação enzimática em suprir a deficiência nutricional das rações valoradas.

Os resultados encontrados estão de acordo com Fischer et al. (2002) e Garcia et al. (2000), os quais suplementaram dietas à base de milho e farelo de soja com complexo enzimático com deficiência nutricional e não encontraram diferenças na conversão alimentar em relação às rações normais.

Os resultados de características de carcaça podem ser observados na Tabela 3.

Houve diferença significativa $(\mathrm{P}<0,05)$ no rendimento de carcaça com a variação da forma física da dieta independente do nível de suplementação enzimática, observando-se melhor rendimento de carcaça nas aves que receberam a ração peletizada.

Houve um aumento linear $(\mathrm{P}<0,05)$ do teor de gordura abdominal na medida em que se aumentou o nível de suplementação enzimática (Figura 4). O aumento dos níveis de enzima resultou numa maior porcentagem de gordura na carcaça das aves, o que pode ser explicado por um possível aumento na liberação de energia dos nutrientes através da suplementação enzimática. $\mathrm{O}$ excesso de energia ingerida além das necessidades teria sido acumulado na forma de gordura na carcaça do frango.

Não houve diferença no rendimento de peito e de coxa e sobrecoxa $(\mathrm{P}>0,05)$ devido aos níveis de suplementação e à forma física da ração. Estes resultados estão de acordo com Zanella (1998), que suplementando dietas à base de milhos e farelo de soja com enzimas, não encontrou diferenças significativas em nenhum dos parâmetros de carcaça avaliados. 
Tabela 3 - Rendimento de carcaça (\%), rendimento de peito (\%), rendimento de coxa e sobrecoxa (\%) e porcentagem de gordura abdominal de frangos de corte alimentados com rações de diferentes formas físicas e níveis de enzimas aos 42 dias de idade.

\begin{tabular}{|c|c|c|c|c|c|c|}
\hline \multicolumn{3}{|c|}{ Rendimento de carcaça (\%) } & & \multicolumn{3}{|c|}{ Gordura abdominal (\%) } \\
\hline & \multicolumn{2}{|c|}{ Forma Física } & \multicolumn{4}{|c|}{ Forma Física } \\
\hline Níveis de Enzima (g/ton) & Far. & Pelet. & Média & Far. & Pelet. & Média $^{1}$ \\
\hline 0 & 74,07 & 75,06 & 74,57 & 1,57 & 1,48 & 1,52 \\
\hline 200 & 74,77 & 76,38 & 75,57 & 1,50 & 1,62 & 1,56 \\
\hline 400 & 74,06 & 75,23 & 74,65 & 1,65 & 1,73 & 1,69 \\
\hline Média & $74,30 \mathrm{~b}$ & $75,56 \mathrm{a}$ & & 1,57 & 1,61 & \\
\hline $\mathrm{CV}(\%)$ & & 2,87 & & & 33,81 & \\
\hline \multicolumn{3}{|c|}{ Rendimento de peito $(\%)$} & & \multicolumn{3}{|c|}{ Rend. de coxa e sobrecoxa (\%) } \\
\hline & \multicolumn{2}{|c|}{ Forma Física } & & \multicolumn{2}{|c|}{ Forma Física } & \\
\hline Níveis de Enzima (g/ton) & Far. & Pelet. & Média & Far. & Pelet. & Média \\
\hline 0 & 29,67 & 30,78 & 30,22 & 30,58 & 29,60 & 30,09 \\
\hline 200 & 31,69 & 31,15 & 31,42 & 30,27 & 30,56 & 30,41 \\
\hline 400 & 31,84 & 30,67 & 31,25 & 30,87 & 29,71 & 30,30 \\
\hline Média & 31,07 & 30,86 & & 30,57 & 29,95 & \\
\hline $\mathrm{CV}(\%)$ & & 7,01 & & & 6,10 & \\
\hline
\end{tabular}

${ }^{1}$ Efeito linear significativo $(\mathrm{P}<0,05)$.

a, b letras minúsculas diferentes nas linhas diferem estatisticamente entre si $(\mathrm{P}<0,05)$.

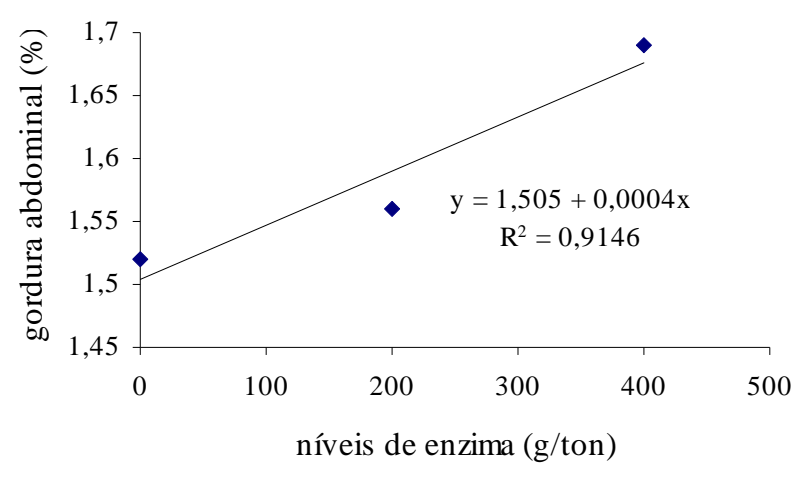

Figura 4 - Teor de gordura abdominal de frangos de corte suplementados com enzimas aos 42 dias.

\section{CONCLUSÕES}

A forma física peletizada proporcionou melhor ganho de peso aos 21 dias e melhor rendimento de carcaça das aves. A utilização do complexo enzimático em rações peletizadas foi influenciada pela desnaturação enzimática decorrentes das temperaturas utilizadas no processo. A energia metabolizável do milho e do farelo de soja podem ser valoradas em 2 e $9 \%$, respectivamente e a digestibilidade de aminoácidos em $4 \%$ para ambos ingredientes na presença do complexo enzimático sem prejudicar o desempenho dos frangos de corte.

\section{REFERÊNCIAS BIBLIOGRÁFICAS}

BRUM, P. A. R. et al. Efeito do nível de trigo na dieta, percentual de gãos germinados e forma física da ração sobre o desempenho de frangos de corte. In: CONFERÊNCIA APINCO DE CIÊNCIA E TECNOLOGIA AVÍCOLAS, 1998, São Paulo. Anais... São Paulo: FACTA, 1998. p. 10.

CAMIRUAGA, M.; GARCIA, F.; ELERA, R.; SIMONETTI, C. Respuesta produtictiva de pollos broilers a la adicion de enzimas exogenas a dietas basadas en maiz o titicale. Ciencia Inv. Agraria, [S.1.], v. 28, n. 1, p. 23-26, 2001.

CONTE, A. J.; TEIXEIRA, A. S.; BERTECHINI, A. G.; FIALHO, E. T.; MUNIZ, J. A. Efeito da fitase e xilanase sobre a energia metabolizável do farelo de arroz integral em frangos de corte. Revista Ciência e Agrotecnologia, Lavras, v. 26, n. 6, p. 1289-1296, 2002.

FERREIRA, D. F. Análises estatísticas por meio do SISVAR para Windows versão 4.0. In: REUNIÃO ANUAL DA REGIÃO BRASILEIRA DA SOCIEDADE INTERANCIONAL DE BIOMETRIA, 2000, São Carlos, SP. Anais... São Carlos: UFSCar, 2000. p. 255-258. 
FISCHER, G.; MAIER, J. C.; RUTZ, F. Desempenho de frangos de corte alimentados com dietas á base de milho e farelo de soja, com ou sem a adição de enzimas. Revista Brasileira de Zootecnia, Viçosa, v. 31, p. $402-$ 410, 2002.

GARCIA, E. R. M.; MURAKAMI, A. E.; BRANCO, A. F. Suplementação enzimática em dietas contendo farelo de soja e soja integral extrusada e efeitos na digestibilidade dos nutrientes, fluxo ileal da digesta e performance de frangos de corte. Revista Brasileira de Zootecnia, Viçosa, v. 29, n. 5, p. 1414-1426, 2000.

PEREIRA, A. S. Response to Allzyme Vegpro in a broiler diet with soy energy, protein and amino acids adjusted by $7 \%$ or added on top at a standart diet. In: BIOTECHNOLOGY INTHE FEED INDUSTRYALLTECH'S ANNUAL SYMPOSIUM, 1999, Nottingham. Proceedings... Nicholasville: Corporate Media Services, 1999. p. 14.

ROLL, V. F. B. Efeito da forma física da ração sobre o desempenho e características de carça de frangos de corte machos criados no verão. 1998. 68 f. Dissertação (Mestrado em Zootecnia) - Universidade Federal de Pelotas, Pelotas, 1998.
ROSTAGNO, H. S.; ALBINO, L. F. T.; DONZELE, J. L. Tabelas brasileiras para aves e suínos: composição de alimentos e exigências nutricionais. Viçosa: UFV, 2000. 141 p.

SCHANG, M. J.; AZCONA, J. O.; ARIAS, J. E. The performance of broilers fed with diets containing Allzyme Vegpro. In: BIOTECHONOLOGY INTHE FEED INDUSTRYALLTECHS ANNUAL SYMPOSIUM, 1997, Nicholasville.Proceedings... Nicholasville: Corporate Media Services, 1997.

TORRES, D. M. et al. Efeitos da suplementação enzimática em dietas á base de milho e soja sobre o desempenho de frangos de corte. In: REUNIÃO ANUAL DA SOCIEDADE BRASILEIRA DE ZOOTECNIA, 38., 2001, Recife. Anais... Recife: UFPE, 2001.

VARGAS, G. D.; BRUM, P. A. R.; FIALHO, F. B.; RUTZ, F.; BORDIM. Alzzyme Vegpro. Revista Brasileira de Agrociência, Pelotas, v. 7, n. 1, p. 42-45, 2001.

ZANELLA, I. Suplementação enzimática em dietas à base de milho e farelo de soja processados sobre a digestibilidade dos nutrientes e desempenho de frangos de corte. 1998. 187 f. Tese (Doutorado em Zootecnia) Faculdade de Ciências Agrárias e Veterinárias, Universidade Estadual Paulista, Botucatu, 1998. 